\title{
The End of the 15-20 Minute Primary Care Visit
}

\author{
Mark Linzer, MD ${ }^{1,2}$, Asaf Bitton, MD, MPH ${ }^{3}$, Shin-Ping Tu, MD, MPH', Margaret Plews-Ogan, MD, $M S^{5}$, \\ Karen R. Horowitz, MD ${ }^{6,7}$, and Mark D. Schwartz, MD for the Association of Chiefs and Leaders in \\ General Internal Medicine (ACLGIM) Writing Group*
}

'Division of General Internal Medicine, Hennepin County Medical Center, Minneapolis, MN, USA; ${ }^{2}$ University of Minnesota, Minneapolis, MN, USA; ${ }^{3}$ Harvard Medical School, Boston, MA, USA; ${ }^{4}$ Virginia Commonwealth University, Richmond, VA, USA; ${ }^{5}$ University of Virginia, Charlottesville, VA, USA; ${ }^{6}$ Louis Stokes Cleveland VAMC, Cleveland, OH, USA; ${ }^{7}$ Case Western Reserve University School of Medicine, Cleveland, OH, USA; ${ }^{8} \mathrm{New}$ York University School of Medicine, New York, NY, USA.

KEY WORDS: Primary care; Time pressure; Burnout; Quality of care; Health policy.

J Gen Intern Med 30(11):1584-6

DOI: $10.1007 / \mathrm{s} 11606-015-3341-3$

c) Society of General Internal Medicine 2015

Sign on a print shop door:

"We can do it fast, we can do it well, we can do it cheap. Pick two."

A 78-year-old widow with hypertension, osteoarthritis, a recent stroke, elevated cholesterol, and a 50-pack-year smoking history comes to her primary care provider for a mild cough and weight loss. She lives alone and loves to chat with her doctor. The physical examination is unrevealing. Chest xray shows a lung nodule. A CT scan is ordered. A long discussion ensues about what would happen if the CT scan shows cancer: how would she undergo evaluation and treatment with her family far away? For what became a 40-min visit, only $15 \mathrm{~min}$ had been allotted. Now the doctor is behind schedule. She feels guilty and gives more time to each patient, thus falling further behind. Screening issues are postponed and personal interactions are diminished. A walk-in patient is added. One waiting patient leaves angrily. At the end of the day, facing a large pile of forms and documentation needs, the

*ACLGIM Writing Group Members (in addition to those listed above) include: Sara Poplau, BA, Minneapolis Medical Research Foundation, Minneapolis, MN; Anuradha Paranjape, MD, MPH, Temple University School of Medicine, Philadelphia, PA; Michael Landry, MD, MSc, New Orleans VAMC and Tulane University, New Orleans, LA; Stewart Babbott, $M D$, University of Kansas, Kansas City, KS; Tracie Collins, MD, MPH, Department of Preventive Medicine and Public Health, University of Kansas, Wichita, KS; T. Shawn Caudill, MD, MSPH, University of Kentucky, Lexington, KY; Arti Prasad, $M D$, and Allen Adolphe, $M D, P h D$, University of New Mexico, Albuquerque, NM; David E. Kern, MD, MPH, Johns Hopkins University School of Medicine, Baltimore, MD; KoKo Aung, MD, MPH, University of Texas Health Science Center at San Antonio, San Antonio, TX; Katherine Bensching, MD, Oregon Health Sciences University, Portland, OR; Kathleen Fairfield, MD, MPH, DrPH, Maine Medical Center, Portland, $M E$, and the Association of Chiefs and Leaders in General Internal Medicine (ACLGIM), Alexandria, VA.

Published online April 22, 2015 doctor feels drained and questions the quality of care she provided.

The Time Crunch. While Mechanic demonstrated that routine primary care visits (averaging 15-20 $\mathrm{min}$ ) were 1 to $2 \mathrm{~min}$ longer than before, ${ }^{1}$ the complexity of clinical issues addressed during these visits has increased. In 2010, the CDC reported that one-third of elderly patients had three or more chronic medical conditions, with $40 \%$ of patients taking three or more medications. Providers may respond by cutting corners on the history and physical examination and by ordering more tests, which lead to a cascade of follow-up tests. Providers describe behind-the-scenes burdens of documentation, phone calls, emails, refills, consultations, and lab reports, while careful calculations show that guideline-driven preventive care would add $7 \mathrm{~h}$ to each primary care clinician's workday. $^{2}$ The work of primary care simply cannot be completed in the time allotted.

Consequences for Patients. Increased work during short (<20 min) visits means appointments in which fewer health care issues are addressed and the depth of understanding is diminished. Time-consuming psychosocial determinants of health are left unaddressed. These consequences translate to decreased patient satisfaction, excess emergency room usage and non-adherence to treatment plans. ${ }^{3}$

Consequences for Providers. Fifty-three percent of primary care providers report time pressure in the clinical encounter. ${ }^{4}$ Many providers describe emotional exhaustion and the fear of making clinical errors. Students observe harried primary care providers and choose alternative career paths.

Root Causes. In the early 1990s, Medicare adopted the relative value unit (RVU) payment model. In a budgetneutral system, the introduction of new procedures at substantially higher RVU levels has resulted in the devaluing of cognitive care such as evaluation and management services. When private insurers and managed care contracts reduced compensation, providers increased daily volumes to maintain stable incomes. Health systems followed with daily visit 
targets. This fee-for-service (FFS) system, poorly constructed for the delivery of comprehensive primary care, has left primary care providers feeling like they are on an assembly line rather than engaged in a mission to heal the sick and prevent serious illness.

Brief visits would suffice if the tasks of primary care had decreased, or if sharing this work with other team members had increased. But this has not been the case. Scientific advances have increased the complexity of diagnostic testing and prescribing, the frequency of care coordination between generalists and subspecialists, and the post-visit workload. Computer work has spiraled, along with an expanded number of reportable performance measures. Electronic medical records (EMRs) have decreased face-to-face time with patients, while "meaningful use" EMR requirements have set forth worthy but time-consuming tasks. To provide patients with the personalized care they seek, a new system is needed.

Suggestions for Broad System Changes. Having flexible encounter times in primary care to meet patient needs will require shifts in both workflow and compensation. We recommend that the routine care of complex primary care patients requires a visit time to meet patient needs, and may be $30 \mathrm{~min}$ or longer. Models should include fees for care management and provide resources for team-based care by nurses, medical assistants, and pharmacists. While alternative payment models are emerging in both public and private sectors, ${ }^{5}$ what is lacking is a systematic approach for providers to respond to these new incentives with strategies that improve outcomes with lower spending. These strategies should include the means to allow sufficient time for patients to feel heard and for providers to deliver high-quality care.

To account for the increasing complexity of primary care, there will need to be a recalibration of the value of cognitive care codes, by both the Relative Value Scale Update Committee, or RUC (who provides the recommendations), and by CMS (who implements them). Updating RVUs for evaluation and management services to give them greater weight would help redirect revenue to primary care, as most alternative payment models, such as patient-centered medical homes and accountable care organizations (ACOs), are still built upon an FFS base.

New payment systems to support longer primary care visits face uphill challenges. First, inadequate care management fees (with extensive time requirements for documentation) often leave practices adrift between the promise of team-based care and the reality of an FFS system (a "foot in two canoes"). Second, due to Medicare Part B's $20 \%$ co-pay mandate, adoption of CMS' care management fees may lead to increased patient co-pays for beneficiaries without supplemental insurance covering this newly reimbursed service. Finally, it will take time and perseverance to change a culture in which practice leaders are accustomed to thinking of fewer visits as a sign of clinicians not working hard.
We believe there are several ways to get from here to there. For one, health care organizations should acknowledge differing care models (FFS versus "total cost of care") operating within the same health system. For example, "ambulatory ICUs" or "intensive primary care" settings have become a popular means to reduce excess utilization. In these models, increased visit time and upfront investments in personnel and resources improve the ability of providers to manage the social and medical needs of high-utilizing patients. These systems are sustainable when integrated business models track dollars spent in the new care model (e.g., on additional team members) and include credits for savings from reduced emergency department and inpatient utilization. Otherwise, providers with low RVU production are penalized for "not working hard enough." These integrated business models will reflect overall cost savings for the institution and will remove "intensive primary care" providers from being evaluated through an FFS lens. Second, alternative payment models could be expanded with new mechanisms to change the basis for clinician payments, such as through the SGR [Sustainable Growth Rate] Repeal and Provider Payment Modernization Act. Third, ACOs, which manage the full continuum of care while being held accountable for costs and quality, may negotiate contracts with additional primary care funding based upon risk adjustment for social and medical characteristics of their populations.

How can practices traverse the change to appropriately timed visits while unbundling activities that could be performed by others? Management approaches, such as LEAN methodology, could be used to streamline primary care visit. These practice transformations will first require evaluating an organization's "capacity for development," or readiness to change, and resources will be needed to reshape the practice's operations and values. While we await these transformations, the provision of primary care will require more time than is currently allotted.

Innovative processes to improve access to care, including patient portals, e-visits, nurse visits, and community health worker (CHW) contacts, are all in development. Providing efficient care to patients during longer visits could avoid shortchanging patient needs, lead to better outcomes, and preserve access by reducing the need for early return appointments.

We anticipate real benefits of allowing sufficient time for primary care, including lower emergency room and hospital utilization, fewer unnecessary referrals, less ill-advised diagnostic testing, and improved patient satisfaction. Better interpersonal communication will also improve clinician satisfaction and well-being, critical components in addressing the current crisis in the shrinking primary care workforce.

In a new model, the same 78 -year-old patient would have had a CHW and a provider with flexible visit times. In this scenario, the CHW had spoken with the patient and reported her cough and weight loss to the doctor. The chest x-ray performed prior to the visit showed a large nodule. In the $30 \mathrm{~min}$ allotted, the doctor had time to empathically discuss 
the findings with the patient, order a CT scan, and collaboratively decide upon a follow-up plan. The doctor did not fall behind in her work day, and other patients were not inconvenienced. It was still a hard day, but it was also rewarding. The medical student working with her was impressed with the compassionate, multidisciplinary care, and decided that this was a career worth pursuing.

Primary care cannot be done fast, well, and cheap. Let's find the ways to appropriately structure it, pay for it, and do it right.

Acknowledgments: We are grateful to Dr. Christine Sinsky for her inspiring comments on a draft of this manuscript. We also thank the editors for their support and insights in developing this final version.

Conflicts of Interest: Dr. Bitton is senior adviser for the Comprehensive Primary Care Initiative at the Center for Medicare and Medicaid Innovation (CMMI). (The views expressed do not reflect the official views of CMS or CMMI). There are no other conflicts of interest among the authors.

Corresponding Author: Mark Linzer, MD; Division of General Internal Medicine Hennepin County Medical Center, 701 Park Ave S (P7), Minneapolis, MN 55415, USA (e-mail: Mark.linzer@hcmed.org).

\section{REFERENCES}

1. Mechanic D, McAlpine DD, Rosenthal M. Are patients' office visits with physicians getting shorter? N Engl J Med. 2001;344:198-204.

2. Yarnall KS, Pollak KL, Ostbye T, Krause KM, Michener JL. Primary care: is there enough time for prevention? Am J Pub Health. 2003;93:635-641.

3. Geraghty EM, Franks P, Kravitz RL. Primary care visit length, quality, and satisfaction for standardized patients with depression. J Gen Intern Med. 2007;22:1641-1647.

4. Linzer M, Manwell L, Williams E, et al. Working conditions in primary care. Ann Intern Med. 2009;151:28-36.

5. Edwards ST, Bitton A, Hong J, Landon BE. Patient-centered medical home initiatives expanded in 2009-13. Health Aff. 2014;33:1823-1831. 